Artigo Original

Original Article

Matheus Sant'Ana Michelino' ${ }^{1}$ Elizeu Coutinho Macedo ${ }^{1}$ (B)

Descritores

Linguagem

Leitura

Analfabetismo

Aprendizagem

Adultos

Keywords

Language

Reading

Illiteracy

Learning

Adults

Endereço para correspondência: Matheus Sant'Ana Michelino Laboratório de Neurociência Cognitiva e Social, Programa de Pós-graduação em Distúrbios do Desenvolvimento, Centro de Ciências Biológicas e da Saúde, Universidade Presbiteriana Mackenzie Rua Piauí, $181,10^{\circ}$ andar, São Paulo (SP), Brasil, CEP: 01241-001. E-mail: matheus.michelino@gmail.com Recebido em: Agosto 16, 2019

\section{Consciência fonológica, nomeação automática rápida e leitura em adultos analfabetos funcionais}

\author{
Phonological awareness, rapid automatized \\ naming, and reading of functionally illiterate \\ adults
}

\section{RESUMO}

Objetivo: O presente estudo tem como objetivo descrever o perfil de adultos analfabetos funcionais em tarefas de leitura, consciência fonológica $(\mathrm{CF})$, e nomeação automática rápida (NAR); bem como correlacionar o desempenho dessas tarefas. Além disso, buscou-se compreender quanto que o desempenho em CF e NAR predizem o resultado em leitura de palavras e pseudopalavras. Método: Foram avaliados 23 adultos analfabetos funcionais em tarefas de inteligência, leitura, CF e NAR. Resultados: Os participantes apresentaram dificuldades em CF, tendo pobre desempenho em tarefas que envolviam análise e manipulação de fonemas. Em NAR, apresentaram maior facilidade na nomeação de itens alfanuméricos. Em relação à leitura, houve dificuldades no processamento fonológico, apresentando erros por troca fonológica. Análises de correlação indicaram que a leitura apresentou maiores correlações com NAR do que com CF. Por fim, a análise de regressão indicou que o desempenho em NAR é capaz de explicar mais da metade do resultado em leitura dos participantes. Conclusão: De modo geral, o perfil dos adultos analfabetos funcionais se caracteriza por apresentar prejuízos nas habilidades avaliadas, sendo esses prejuízos mais evidentes em CF ao nível dos fonemas, bem como na nomeação de itens não-alfanuméricos. Além disso, os resultados em NAR explicam melhor os resultados de leitura de palavras e pseudopalavras do que os resultados em CF.

Trabalho realizado no Laboratório de Neurociência Cognitiva e Social, Centro de Ciências Biológicas e da Saúde - CCBS, Universidade Presbiteriana Mackenzie - São Paulo (SP), Brasil.

${ }^{1}$ Laboratório de Neurociência Cognitiva e Social, Programa de Pós-graduação em Distúrbios do Desenvolvimento, Centro de Ciências Biológicas e da Saúde, Universidade Presbiteriana Mackenzie - São Paulo (SP), Brasil.

Fonte de financiamento: FAPESP - 2015/22664-3.

Conflito de interesses: nada a declarar. 


\section{INTRODUÇÃO}

De acordo com a United Nations Educational, Scientific and Cultural Organisation (UNESCO), o analfabetismo é definido como a incapacidade de ler ou escrever um enunciado simples relacionado a sua vida diária, sendo que $14 \%$ da população mundial, com mais de 15 anos, são incapazes de ler textos simples ${ }^{(1)}$. No Brasil, dados de 2018 indicam que 11,3 milhões $\left(6,8 \%\right.$ da população) de adultos são analfabetos ${ }^{(2)}$. No entanto, essa taxa é ainda maior se forem considerados os analfabetos funcionais.

$\mathrm{O}$ analfabetismo funcional diz respeito à incapacidade de compreender, utilizar e julgar informações contidas em materiais escritos de uso corrente para alcançar objetivos, ampliar conhecimentos e participar da sociedade ${ }^{(3)}$. No Brasil, cerca de $29 \%$ da população adulta pode ser classificada como analfabetos funcionais, ou seja, apresentam dificuldades para fazer uso da leitura e da escrita em situações da vida cotidiana, como ler um cartaz ${ }^{(3)}$. Tais estudos de prevalência são importantes para avaliar os impactos econômicos e sociais da ausência de uma leitura proficiente. No entanto, esses achados são pouco esclarecedores sobre os diferentes perfis cognitivos e linguísticos dessa população. Por exemplo, ainda não está claro se parte das dificuldades de leitura observadas nessa população se relacionam com alterações no processamento fonológico, tal como observado em estudos com crianças.

Processamento fonológico se refere ao uso da informação fonológica no processamento da linguagem oral e escrita. Essa habilidade é formada por três componentes principais: consciência fonológica, avaliada por tarefas como adicionar, deletar e isolar sons de uma palavra; acesso lexical ao código fonológico, avaliado por tarefas de nomeação automática rápida; e por fim, memória de trabalho fonológica, avaliada por tarefas que envolvem o armazenamento e a manipulação de uma informação fonológica por um breve período ${ }^{(4)}$. Esses componentes se correlacionam de maneira independente (mas integrada) com o desempenho em leitura, sendo que alterações nessas habilidades impactam na aquisição e desempenho de leitura ${ }^{(5)}$. No entanto, a consciência fonológica e a nomeação automática rápida apresentam maior impacto na aquisição da leitura, bem como maiores correlações com as dificuldades de leitura( ${ }^{(6)}$.

A consciência fonológica (CF) é a capacidade de identificar e manipular segmentos dos sons da fala. Essa habilidade está relacionada com a decodificação fonológica, ou seja, o mapeamento da linguagem oral e sua ortografia ${ }^{(6)}$. Já a nomeação automática rápida (NAR) é a capacidade de nomear mais rapidamente e com precisão uma série de estímulos visuais familiares, que podem ser não alfanuméricos (geralmente cores ou objetos) ou alfanuméricos (geralmente letras ou números) ${ }^{(6)}$. O tempo total de nomeação é interpretado como um indicativo da automatização pelo qual os estímulos visuais e seus códigos fonológicos são integrados, recuperados e nomeados ${ }^{(6)}$. Adultos com pobres habilidades de leitura apresentam déficits nas duas habilidades apresentadas.

Em relação à $\mathrm{CF}$, adultos analfabetos apresentam dificuldades, principalmente ao nível de consciência dos fonemas, que se relaciona com a baixa habilidade em leitura ${ }^{(7,8)}$. Assim, apresentam pior desempenho em tarefas de adição e subtração de fonemas iniciais de palavras e pseudopalavras quando comparados com adultos alfabetizados tardiamente, indicando que a habilidade de lidar explicitamente com unidades fonêmicas não se desenvolve espontaneamente, mas sendo dependente da aprendizagem de leitura ${ }^{(8)}$. Entretanto, essa dificuldade não é verificada em tarefas que envolvem detecção de sílabas e de rimas, indicando que a sensibilidade à rima e a análise de sílabas podem se desenvolver até algum ponto na ausência da experiência normalmente fornecida pela instrução de leitura ${ }^{(8)}$. Esses resultados recebem suporte de evidências de estudos experimentais, que investigaram os efeitos de intervenções em leitura com foco no ensino da correspondência entre grafemas e fonemas ${ }^{(7,9,10)}$. Dessa forma, adultos que aprendem a ler ou melhoram o nível de leitura, apresentam maior habilidade de consciência fonológica ao nível dos fonemas.

Já em relação a NAR, poucos estudos investigaram a relação entre nomeação e leitura em adultos analfabetos funcionais. Em um desses estudos ${ }^{(11)}$ foram avaliados adultos analfabetos, adultos tardiamente alfabetizados e adultos que foram alfabetizados quando crianças. Assim, adultos analfabetos levaram mais tempo para nomear os itens do que os outros dois grupos de adultos. Além disso, os dois grupos de adultos alfabetizados não diferiram um do outro. Tais resultados sugerem que aprender a ler, independente da escolaridade ou da idade de alfabetização facilita o acesso lexical. Esse efeito facilitador específico não pode ser atribuído à educação geral, mas é uma consequência da alfabetização. Dessa forma, a aprendizagem da leitura faz com que se fortaleça as interconexões entre representações fonológicas e ortográficas, promovendo uma recuperação mais eficiente das palavras, como refletido no melhor desempenho dos grupos de leitores sobre os analfabetos ${ }^{(11)}$. Além disso, são encontradas correlações do tempo de NAR com leitura de palavras e compreensão de textos em adultos analfabetos funcionais ${ }^{(12,13)}$.

Tendo em vista que a condição de analfabetismo funcional impacta o desenvolvimento econômico, social e cognitivo, são necessários mais estudos para a compreensão desse fenômeno. Dessa forma, o presente estudo tem como objetivo descrever o perfil de adultos analfabetos funcionais em tarefas de leitura, consciência fonológica, e nomeação automática rápida; bem como correlacionar o desempenho dessas tarefas. Além disso, buscou-se compreender quanto que o desempenho em consciência fonológica e nomeação automática rápida predizem o resultado em leitura de palavras e pseudopalavras.

\section{MÉTODO}

Os participantes foram esclarecidos sobre os objetivos e métodos do estudo e só participaram os que concordaram e assinaram o Termo de Consentimento Livre e Esclarecido (TCLE). O TCLE foi lido em voz alta para cada um dos participantes e eventuais dúvidas foram esclarecidas pelo pesquisador. O estudo foi submetido e aprovado pelo Comitê de Ética da Universidade (CAAE: 55505816.4.0000.0084; parecer: 1.559.697; data: 25/05/2016). 


\section{Participantes}

Os participantes foram recrutados em uma escola de Alfabetização e Educação de Jovens e Adultos (AEJA) da região central da cidade de São Paulo e em uma empresa de limpeza que presta serviços à universidade.

A amostra foi composta por 23 adultos (14 mulheres) com ensino fundamental incompleto e dificuldades de leitura. A idade dos participantes variou entre 18 e 60 anos, $(M=41,61$; $D p=9,96)$, caracterizando assim uma amostra representativa de alunos de $\mathrm{AEJA}^{(14)}$.

Foram incluídos adultos que não acertaram todos os itens do Teste de Competência de Leitura de Palavras e Pseudopalavras ${ }^{(15)}$, sendo que a pontuação máxima neste teste corresponde a alunos do primeiro ano do Ensino Fundamental II. Assim, participantes que acertaram os 70 itens, foram excluídos do estudo.

\section{Instrumentos}

\section{Avaliação de inteligência}

Escala Wechsler Abreviada de Inteligência - WASI: avalia de forma breve a habilidade intelectual através de 4 subtestes: vocabulário, semelhanças, cubos e raciocínio matricial. Os subtestes avaliam domínios cognitivos como conhecimento verbal, processamento de informação visual, raciocínio espacial e não verbal, inteligência fluída e cristalizada ${ }^{(16)}$, e possibilitam estimar os QIs total, verbal e de execução. A escala foi aplicada e corrigida por um psicólogo.

\section{Instrumentos para avaliação do nível de leitura}

Teste de Competência de Leitura de Palavras e Pseudopalavras (TCLPP): avalia a competência de leitura silenciosa de palavras e pseudopalavras. É composta por 78 itens, sendo os oito primeiros de treino. Cada item é composto por uma figura e uma palavra ou pseudopalavra escrita abaixo, e a pessoa deve indicar se a correspondência da palavra e da figura está correta ou incorreta. Os itens são divididos nos seguintes tipos: 1) palavras corretas regulares (CR), como FADA sob a figura de uma fada; 2) palavras corretas irregulares (CI), como TÁXI, sob a figura de um táxi; 3) palavras com trocas semânticas (TS), como TREM, sob a figura de um ônibus; 4) pseudopalavras homófonas (PH), como PÁÇARU sob a figura de um pássaro; 5) pseudopalavras com trocas visuais (TV), como CAEBÇA, sob a figura de uma cabeça; 6) pseudopalavras com trocas fonológicas (TF), como CANCURU sob a figura de um canguru; 7) pseudopalavras estranhas (PE), como RASSUNO sob a figura de uma mão ${ }^{(15)}$. Foram considerados os números de acertos, sendo 70 a pontuação máxima total e 10 o número de acertos máximos para cada um dos 7 subtestes.

Prova de Leitura de Palavras e Pseudopalavras Isoladas: A prova foi desenvolvida para o presente estudo a partir da lista de palavras e pseudopalavras elaborada por Lukasova ${ }^{(17)}$ e foi composta por uma lista de palavras e uma de pseudopalavras, com 36 itens cada. As palavras foram selecionadas em função da frequência (alta e baixa frequência), comprimento (curtas e longas) e regularidade (regulares, regra e irregulares). Cada item era apresentado sequencialmente e o participante deveria ler em voz alta. As respostas foram gravadas em arquivos de áudio e a correção foi realizada posteriormente, sendo que a leitura do item poderia ser ou não correta. Dessa forma, a pontuação em cada lista variou de 0 a 36.

Prova de Leitura de Texto: Formado por 12 textos com grau crescente de número de palavras, mas com grau de legibilidade adequado para os primeiros anos do Ensino Fundamental, calculado a partir do índice Flesch ${ }^{(18)}$. Os 12 textos foram divididos em 3 blocos com 4 textos cada, em função da extensão: bloco 1) textos com 25 palavras em média e Índice Flesch de 85, 17; bloco 2) textos com 45 palavras em média e Índice Flesch de 81,4; e bloco 3) 116 palavras em média por texto e Índice Flesch de 85,17 . Os textos foram construídos pelos autores e deveriam ser lidos em voz alta. A fim de avaliar a compreensão, o avaliando respondia 3 perguntas literais relacionadas a cada um dos textos, em que as respostas estavam explicitamente apresentadas. Por exemplo, em um texto cujo tema era "a galinha dos ovos de ouro", uma das questões era "a galinha botava ovos de que?". Foram atribuídos 1 ponto para respostas corretas e 0 para incorretas. Caso não acertasse todas as 3 questões do texto, a aplicação era interrompida para não expor os participantes à eventuais constrangimentos. A pontuação variou de 0 a 36 pontos.

\section{Linguagem oral}

Prova de Consciência Fonológica por Produção Oral (PCFO): avalia a habilidade do participante manipular sons da fala, expressando oralmente o resultado da manipulação. Apresenta dez subtestes: síntese e segmentação silábica, síntese e segmentação fonêmica, julgamento de rimas e aliterações, manipulação silábica e fonêmica e transposição silábica e fonêmica. Também foram criadas duas variáveis: Atividades Silábicas, que é a soma dos quatro subtestes silábicos, e Atividades Fonêmicas, que é a soma dos quatro subtestes fonêmicos. Para as análises, foram considerados os seguintes critérios de pontuação: pontos brutos totais, ou seja, o número de acertos em todos os subtestes, variando de 0 a 40; pontos brutos em cada um dos subtestes, variando de 0 a 4; por fim, pontos brutos das Atividades Silábicas e Fonêmicas, variando de 0 a 16 pontos cada ${ }^{(19)}$.

Teste de Nomeação Automática (TENA): O TENA é administrado individualmente para estimar a habilidade de ver um símbolo e nomeá-lo acuradamente e rapidamente. O teste é formado por 4 subtestes: cores, objetos, letras e números. Os estímulos são repetidos randomicamente 10 vezes em cada uma das 5 linhas, totalizando 50 estímulos por prancha. $\mathrm{O}$ sujeito deveria nomear cada item o mais rápido possível sem cometer erros. Foram registrados o tempo total de nomeação (em segundos) para cada uma das pranchas. Além do tempo por prancha, foram registradas as seguintes medidas: TENA Total, que é a média de tempo de todos os quatro subtestes; TENA Não Alfanumérico, que é a média de tempo nos subtestes Cores e Objetos; e TENA Alfanumérico, que é a média de tempo nos subtestes Letras e Números ${ }^{(20)}$. 


\section{Procedimentos}

Foram realizados dois encontros individuais com cada participante. No primeiro encontro, após a assinatura do TCLE, foram aplicados o WASI, TCLPP, Prova de Leitura de Palavras e Pseudopalavras Isoladas e PCFO. Uma semana depois, no segundo encontro, foram aplicadas o TENA e a Prova de Leitura de Textos. Cada encontro teve duração média de 75 minutos.

\section{Análise dos resultados}

Foram realizadas análises estatísticas descritivas, reportando a média, desvio padrão e os valores mínimos e máximos em cada uma das medidas estudadas. ANOVA de medidas repetidas foram conduzidas para verificar a existência de diferença entre as médias de acertos em cada tipo de item do TCLPP. Testes $\mathrm{t}$ para amostras pareadas foram conduzidas para comparar diferenças na leitura entre palavras e pseudopalavras na Prova de Leitura de Palavras e Pseudopalavras, assim como para verificar diferenças entre as atividades fonêmicas e silábicas na PCFO e os itens alfanuméricos e não alfanuméricos do TENA. Ademais, foram conduzidas correlações de Pearson entre o desempenho em consciência fonológica e nomeação automática rápida com os resultados das provas envolvendo leitura. Por fim, análise de regressão hierárquica com método Enter foi conduzida, com o objetivo de verificar o efeito da pontuação total da TENA, da PCFO e idade nos resultados em leitura no TCLPP. Para todos os testes, foi estabelecido nível de significância de 5\%. As análises estatísticas foram feitas no programa IBM SPSS Statistics versão 22.

\section{RESULTADOS}

A avaliação do nível de inteligência, realizada pelo WASI, indicou que os participantes tiveram como resultado uma média de QI Total de 68,87 (DP=11,81), o que é classificado como extremamente baixo. Desempenho abaixo da média também foi observado nos resultados do QI Execução $(M=73,04 ; D p=13,64)$ e no QI Verbal $(M=70,91 ; D p=10,92)$. Além disso, $50 \%$ ou mais dos participantes encontram-se na faixa extremamente baixa de classificação de inteligência (QI abaixo de 69).

A fim de comparar o desempenho dos participantes de acordo com a média de cada ano escolar, as pontuações brutas dos participantes foram analisadas com base nos dados normativos do TCLPP para alunos do Ensino Fundamental. Dessa forma, o escore bruto de um participante adulto era comparado com a pontuação média de cada ano escolar das crianças, sendo identificada a série do Ensino Fundamental, cujo desempenho era compatível. A Tabela 1 apresenta os pontos brutos obtidos em cada um dos tipos de itens, assim como para o escore total no TCLPP.

Dessa forma, 19 participantes (82,6\%) tiveram um desempenho semelhante ao de alunos do $5^{\circ}$ ano do Ensino Fundamental; 2 participantes $(8,7 \%)$ com desempenho semelhante ao de alunos do $4^{\circ}$ ano; 1 participante $(4,3 \%)$ com desempenho equivalente ao de alunos do $3^{\circ}$ ano; por fim, 1 (4,3\%) participante teve desempenho equiparável ao de alunos do $2^{\circ}$ ano. Para investigar a existência de diferenças entre as médias de acertos em cada tipo de item do TCLPP, ANOVA de medidas repetidas foi conduzida. Resultados indicam diferenças significativas entre os itens $\left(F(2,65)=7,425 ; p=<0,001 ; \eta_{p}{ }^{2}=0,252\right)$. Análises $p o s t$ hoc Bonferroni mostram que o desempenho dos participantes em VF foi inferior ao desempenho em CR, VS e PE.

$\mathrm{Na}$ Prova de Leitura de Palavras e Pseudopalavras, Teste $\mathrm{t}$ para amostras pareadas indicou maior taxa de acerto nas palavras do que nas pseudopalavras $(t(21)=9,09, p<0,001)$. A Tabela 2 apresenta os resultados dos participantes em acertos na Prova de Leitura de Palavras e Pseudopalavras, assim como o total de acertos nas questões de compreensão da Prova de Leitura de Textos. Assim, apenas um participante não conseguiu ler qualquer palavra ou pseudopalavra da lista. Além disso, apenas 2 participantes não conseguiram ler nenhum dos textos do Bloco 1.

$\mathrm{Na}$ PCFO, Teste t para amostras pareadas indicou que maior dificuldade nas atividades fonêmicas do que nas silábicas $(t(22)=13,23 ; p<0,001)$. Já para o TENA, a tempo de nomeação dos alfanuméricos foi menor que os não alfanuméricos $(t(22)=9,87$; $p<0,001)$. Considerando que o TENA é um instrumento que visa avaliar a habilidade de NAR de crianças, os resultados dos participantes foram comparados com os dados normativos da faixa etária mais elevada disponível no manual do teste, ou seja, 9 anos e 11 meses $^{(20)}$. De modo geral, os adultos obtiveram um melhor desempenho do que as crianças em cada um dos subtestes. Em Cores, 75,1\% dos participantes tiveram um resultado acima da média; em Objetos, $87,7 \%$ foram acima da média; em Letras, $62,8 \%$; por fim, em Números, $71,1 \%$ foram

Tabela 1. Estatísticas descritivas do desempenho dos participantes no TCLPP, considerando o número de acertos em cada tipo de item e no total

\begin{tabular}{ccccc}
\hline & Média & $\begin{array}{c}\text { Desvio } \\
\text { Padrão }\end{array}$ & Mínimo & Máximo \\
\hline TCLPP Total (Máx=70) & 61,91 & 6,89 & 41 & 69 \\
TCLPP CR (Máx=10) & 9,39 & 0,72 & 8 & 10 \\
TCLPP CI (Máx=10) & 9,04 & 1,14 & 6 & 10 \\
TCLPP VS (Máx=10) & 9,26 & 1,01 & 6 & 10 \\
TCLPP VV (Máx=10) & 8,52 & 1,53 & 5 & 10 \\
TCLPP VF (Máx=10) & 7,65 & 2,20 & 2 & 10 \\
TCLPP PH (Máx=10) & 8,26 & 2,26 & 3 & 10 \\
TCLPP PE (Máx=10) & 9,52 & 1,31 & 4 & 10 \\
\hline
\end{tabular}

Legenda: TCLPP: Teste de Competência de Palavras e Pseudopalavras; CR: Palavra Correta Regular; Cl: Palavra Correta Irregular; VS: Pseudopalavra Vizinha Semântica; VV: Pseudopalavra Vizinha Visual; VF: Pseudopalavra Vizinha Fonológica; PH: Pseudopalavra homófona; PE: Pseudopalavra Estranha

Tabela 2. Estatísticas descritivas do desempenho dos participantes na Prova de Leitura de Palavras e Pseudopalavras (total de acertos) e Prova de Leitura de Textos (total de acertos das questões de compreensão)

\begin{tabular}{ccccc}
\hline & Média & $\begin{array}{c}\text { Desvio } \\
\text { Padrão }\end{array}$ & Mínimo & Máximo \\
\hline $\begin{array}{c}\text { Leitura de Palavras } \\
\text { (Acertos, Máx=36) }\end{array}$ & 29,73 & 8,54 & 0 & 36 \\
$\begin{array}{c}\text { Leitura de Pseudopalavras } \\
\text { (Acertos, Máx=36) }\end{array}$ & 21,50 & 8,84 & 0 & 32 \\
$\begin{array}{c}\text { Leitura de Textos (total de } \\
\text { acertos, Máx=36) }\end{array}$ & 24,00 & 10,02 & 0 & 36 \\
\hline
\end{tabular}


acima da média das crianças. A Tabela 3 apresenta as estatísticas descritivas para a PCFO e para o TENA.

De modo geral, os escores em PCFO e TENA correlacionaramse significativamente com as diversas medidas de leitura, tendo essas correlações um tamanho de efeito que variaram entre efeito médio $(r>0,30)$ e grande $(r>0,50)$. Mais importante, é possível observar que as medidas de PCFO e TENA correlacionaramse de maneiras diferentes com as provas de leitura. TENA Alfanumérico foi a variável que apresentou as maiores correlações com todas as medidas de leitura. A Prova de Leitura de Textos (compreensão) apresentou correlações mais fortes com TENA do que com PCFO. E na amostra estudada, PCFO Fonêmico foi a medida que teve menos correlação com leitura. A Tabela 4 apresenta as correlações entre as duas provas.

Por fim, a análise de regressão hierárquica com método Enter foi conduzida com o objetivo de verificar o efeito da pontuação total da TENA, da PCFO e idade nos resultados em leitura no TCLPP. Análises sugerem a existência de dois modelos. No primeiro modelo, o desempenho em TENA Total explica $56 \%$ da variância no TCLPP. Já o segundo modelo, que inclui o desempenho de PCFO e a variação de idade, não indicou nenhum acréscimo na variância do TCLPP, demonstrando que na amostra estudada, as variáveis PCFO Total e idade não contribuíram para estimar o escore no teste. Os dois modelos apresentaram significância menor do que 0,001 . A Tabela 5 apresenta os resultados das regressões.

Tabela 3. Estatísticas descritivas do desempenho dos participantes na PCFO (total de acertos) e no TENA (tempo de nomeação, em segundos)

\begin{tabular}{ccccc}
\hline & Média & Desvio Padrão & Mínimo & Máximo \\
\hline PCFO Total (Máx=40) & 26,09 & 6,5 & 13,00 & 1,00 \\
PCFO Rima (Máx=4) & 3,3 & 0,97 & 2,00 & 4,00 \\
PCFO Aliteração (Máx=4) & 3,52 & 0,73 & 4,00 & 4,00 \\
PCFO Sínt. Silábica (Máx=4) & 4,00 & 0,00 & 2,00 & 4,00 \\
PCFO Seg. Silábica (Máx=4) & 3,74 & 0,61 & 2,00 & 4,00 \\
PCFO Mani. Silábica (Máx=4) & 3,48 & 0,73 & 0,00 & 4,00 \\
PCFO Transp. Silábica (Máx=4) & 2,65 & 1,43 & 0,00 & 4,00 \\
PCFO Sínt. Fonêmica (Máx=4) & 1,35 & 0,98 & 0,00 & 3,00 \\
PCFO Seg. Fonêmica (Máx=4) & 0,52 & 1,16 & 0,00 & 4,00 \\
PCFO Mani. Fonêmica (Máx=4) & 2,39 & 1,53 & 0,00 & 4,00 \\
PCFO Transp. Fonêmica (Máx=4) & 1,13 & 1,66 & 9,00 & 4,00 \\
PCFO Ativ. Silábicas (Máx=16) & 13,86 & 2,26 & 1,00 & 16,00 \\
PCFO Ativ. Fonêmicas (Máx=16) & 5,39 & 3,93 & 21,40 & 15,00 \\
TENA Total & 32,32 & 7,44 & 27,60 & 48,57 \\
TENA Cores & 40,06 & 10,28 & 20,37 & 64,60 \\
TENA Objetos & 34,93 & 8,55 & 14,13 & 60,23 \\
TENA Letras & 26,99 & 8,75 & 16,90 & 49,93 \\
TENA Números & 27,29 & 6,48 & 26,22 & 42,87 \\
TENA Não Alfanumérico & 37,49 & 8,40 & 15,52 & 54,57 \\
TENA Alfanumérico & 27,14 & 7,27 & 43,05
\end{tabular}

Legenda: PCFO: Prova de Consciência Fonológica por Produção Oral; TENA: Teste de Nomeação Automática

Tabela 4. Correlação entre o PCFO (Total, Silábico e Fonêmico) e TENA (Total, Não Alfanumérico e Alfanumérico) e as provas de leitura

\begin{tabular}{|c|c|c|c|c|c|c|}
\hline & PCFO Total & PCFO Silábico & PCFO Fonêmico & TENA Total & $\begin{array}{c}\text { TENA Não } \\
\text { Alfanumérico }\end{array}$ & $\begin{array}{c}\text { TENA } \\
\text { Alfanumérico }\end{array}$ \\
\hline TCLPP Total & $0,647^{\star \star}$ & $0,538^{* *}$ & $0,530^{\star *}$ & $-0,765^{\star \star}$ & $-0,649^{* *}$ & $-0,816^{\star *}$ \\
\hline Leitura de Palavras & $0,565^{\star \star}$ & $0,599^{\star *}$ & 0,346 & $-0,715^{\star \star}$ & $-0,619^{\star *}$ & $-0,749^{\star \star}$ \\
\hline Leitura de Pseudo & $0,744^{\star \star}$ & $0,702^{\star \star}$ & $0,537^{\star \star}$ & $-0,790^{\star *}$ & $-0,727^{\star \star}$ & $-0,778^{\star \star}$ \\
\hline Leitura de Textos (compreensão) & $0,427^{*}$ & 0,405 & 0,303 & $-0,704^{\star \star}$ & $-0,569^{\star \star}$ & $-0,783^{\star \star}$ \\
\hline
\end{tabular}

${ }^{*}$ Correlação é significativa ao nível de 0,05 **Correlação é significativa ao nível de 0,01 Legenda: PCFO: Prova de Consciência Fonológica por Produção Oral; TENA: Teste de Nomeação Automática; TCLPP: Teste de Competência de Palavras e Pseudopalavras

Tabela 5. Análise de regressão hierárquica do desempenho no TCLPP e os coeficientes de regressão do TENA Total, PCFO Total e Idade

\begin{tabular}{|c|c|c|c|c|c|c|}
\hline \multicolumn{2}{|c|}{ Modelo } & $\beta$ & $t$ & $p$ & $R^{2}$ & $R^{2}$ Ajustado \\
\hline \multicolumn{7}{|l|}{1} \\
\hline & TENA Total & $-0,765$ & $-5,440$ & $<0,001$ & 0,58 & 0,56 \\
\hline \multicolumn{7}{|c|}{2} \\
\hline & TENA Total & $-0,517$ & $-2,255$ & 0,036 & & \\
\hline & PCFO Total & 0,250 & 1,186 & 0,250 & 0,62 & 0,56 \\
\hline & Idade & 0,162 & 1,014 & 0,323 & & \\
\hline
\end{tabular}

Legenda: PCFO: Prova de Consciência Fonológica por Produção Oral; TENA: Teste de Nomeação Automática; $\beta$ : parâmetros do modelo de

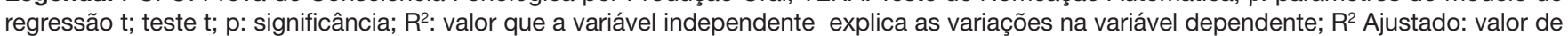
$\mathrm{R}^{2}$ associado à análise de resíduos. 


\section{DISCUSSÃO}

O presente estudo teve como objetivo descrever o perfil de desempenho de uma amostra de adultos analfabetos funcionais em tarefas de consciência fonológica, nomeação automática rápida e leitura. Também teve como objetivo correlacionar o desempenho em consciência fonológica e nomeação automática rápida com os resultados das provas de leitura. Por fim, o estudo buscou compreender o quanto o desempenho em consciência fonológica e nomeação automática rápida predizem o resultado em leitura de palavras e pseudopalavras.

Inicialmente, a avaliação do nível de inteligência indicou que a média de desempenho do grupo pode ser classificada como extremamente baixa. Esse resultado era esperado, dado que a escolarização formal, nível educacional e anos de escolaridade estão correlacionadas com o desempenho em testes de inteligência ${ }^{(21,22)}$. De fato, todos os participantes do estudo apresentavam uma pobre escolarização formal, já que haviam abandonado a escola durante o ensino fundamental quando crianças e estavam em processo de retomada dos estudos. Nessa direção, Yassuda e colaboradores ${ }^{(2)}$ avaliaram a inteligência de 3 grupos de adultos com diferentes níveis de escolaridade e observaram que o grupo de menor escolaridade foi o que apresentou pior desempenho na Escala Wechsler de Inteligência para Adultos - WAIS-R. Dessa forma, sugerem que medidas de inteligência são fortemente influenciadas pelo nível educacional e anos de escolaridade. Visando avaliar o impacto da aprendizagem de leitura no desenvolvimento da inteligência, Landgraf e colaboradores ${ }^{(23)}$ avaliaram a inteligência cristalizada e fluida de adultos analfabetos antes e depois de um ano de aulas de alfabetização. Os resultados mostraram que a aprendizagem da leitura promoveu uma melhora na inteligência cristalizada que está relacionada com contextos educacionais e socioculturais, mas não na inteligência fluida, que se relaciona com a capacidade de encontrar soluções para problemas complexos em novas situações. No entanto, a avaliação de inteligência de adultos analfabetos funcionais deve ser analisada com parcimônia, uma vez que boa parte dos instrumentos demandam domínio linguístico, já que apresentam itens de natureza verbal na sua aplicação.

Existe uma carência de instrumentos de avaliação de leitura e escrita desenvolvidos especificamente para população adulta com baixas habilidades de leitura. Assim, o uso de instrumentos desenvolvidos para crianças pode ser uma alternativa, já que possuem uma menor complexidade e, geralmente, menor tempo de aplicação, o que acaba sendo menos frustrante para os participantes avaliados ${ }^{(24)}$. Dessa forma, o TCLPP foi desenvolvido baseado na identificação de estratégias de leitura e pode ser usado para avaliação de adultos. No presente estudo, observou-se que o desempenho geral dos participantes foi semelhante ao de crianças do $5^{\circ}$ ano do ensino fundamental. Os itens do tipo VF (pseudopalavras com trocas fonológicas) foram os que apresentaram as menores taxas de acerto, o que pode indicar falta de recurso ao léxico ortográfico, mas com o agravante de dificuldades adicionais no próprio processamento fonológico durante a leitura. Esse resultado levanta a hipótese de que parte das dificuldades encontradas em adultos analfabetos funcionais pode ser explicada pelo desenvolvimento prejudicado do estágio alfabético e da rota fonológica de leitura ${ }^{(15)}$. Um padrão semelhante de respostas tem sido encontrado em crianças com dislexia, no qual apresentam pior desempenho na leitura de pseudopalavras com trocas fonológicas ${ }^{(25,26)}$. Em suma, mesmo sendo desenvolvido para crianças, o TCLPP se mostrou útil para avaliação de adultos analfabetos funcionais, indicando dificuldade no processamento fonológico.

Uma das habilidades metalinguísticas relacionadas com a aprendizagem e desempenho em leitura é a consciência fonológica( ${ }^{(6)}$. Nesse sentido, foi observado maiores dificuldades em atividades fonêmicas do que nas silábicas. Estudos conduzidos com adultos analfabetos e adultos analfabetos funcionais mostram esse mesmo padrão ${ }^{(7-10)}$. Evidências sugerem que essa habilidade se desenvolve das maiores para as menores unidades linguísticas. Sendo assim, formas precoces de consciência fonológica (por exemplo, consciência de sílaba, aliteração e rima) se desenvolvem sem ensino explicito e antes da aprendizagem de leitura ${ }^{(27)}$. Já a habilidade de lidar explicitamente com unidades fonêmicas não se desenvolve espontaneamente, sendo dependente da aprendizagem e desempenho de leitura ${ }^{(8)}$. Conforme os adultos aprendem a ler ou melhoram o nível de leitura, a performance em consciência fonológica ao nível dos fonemas também melhora. De fato, a relação entre consciência dos fonemas e leitura é bidirecional, ou seja, a experiência em leitura não é apenas influenciada pelo desempenho em consciência fonológica ao nível dos fonemas, mas também o influencia, indicando uma codependência entre essas habilidades ${ }^{(28)}$. Os resultados do presente estudo confirmam essas evidências, pois a amostra de adultos analfabetos funcionais apresentou pobre desempenho em análise e segmentação de fonemas, mesmo que o instrumento utilizado para avaliar CF tenha sido desenvolvido para crianças e, teoricamente, apresente menor dificuldade. Assim, é possível conjecturar que o baixo desempenho nas tarefas fonêmicas dos analfabetos funcionais pode ter sido influenciado pelo seu baixo desempenho e a pouca experiência com leitura.

Outra habilidade relacionada com desempenho em leitura é a nomeação automática rápida. De modo geral, o tempo médio de nomeação foi inferior ao de crianças com 9 anos e 11 meses em todos os subtestes, indicando que eles obtiveram um melhor desempenho na tarefa. Esses resultados estão parcialmente de acordo com o estudo de Corrêa ${ }^{(29)}$, no qual foi observado adultos brasileiros que estavam sendo alfabetizados tardiamente e tiveram seu desempenho em tarefas de NAR comparados com crianças pareadas por nível de leitura. Os adultos em processo de alfabetização tiveram desempenho superior apenas no tempo de nomeação de objetos e dígitos, enquanto o desempenho em letras e cores foi semelhante ao das crianças. Resultados semelhantes foram encontrados em um estudo com analfabetos funcionais alemães, que tiveram suas habilidades linguísticas, cognitivas e numéricas avaliadas e comparadas com dados normativos provenientes de estudos com crianças. Em uma tarefa de nomeação rápida, os analfabetos funcionais foram mais lentos que as crianças de $5^{\circ}$ a $8^{\circ}$ ano ${ }^{(24)}$. Apesar do presente estudo não ter feito nenhum comparativo entre grupos de crianças e adultos, pode-se afirmar que o desempenho dos adultos analfabetos funcionais foi superior ao das crianças que 
participaram do estudo de normatização do TENA em todos os subtestes. Uma limitação do estudo foi a de não comparar o desempenho dos participantes em nomeação automática rápida com uma amostra de adultos plenamente alfabetizados. Ainda em relação a caracterização do desempenho dos participantes, observa-se melhor desempenho nos itens alfanuméricos do que os não alfanuméricos. Uma possível hipótese para explicar essa discrepância é de que adultos, independentemente do nível de leitura, utilizam muito mais representações numéricas em seu cotidiano (ex: ao manejar dinheiro) do que representações de cores e objetos.

Em relação às análises de correlação, verifica-se que o desempenho em CF e NAR estão correlacionados com as diversas medidas de leitura. Entretanto, observa-se que a nomeação dos itens alfanuméricos foi o que se correlacionou de maneira mais forte com leitura, principalmente com leitura e compreensão de textos. Isso indica que, para a população de adultos analfabetos funcionais, nomeação automática rápida parecer ser uma habilidade que se relaciona mais com o desempenho em leitura.

Isso também é verificado nos resultados da análise de regressão, tendo em vista que o desempenho total em NAR foi responsável por explicar 56\% do desempenho dos participantes em leitura de palavras e pseudopalavras. Em vista da magnitude deste resultado, levanta-se a hipótese de que o treino em NAR pode ter um impacto muito grande na aprendizagem da leitura em população de adultos. Um estudo recente, realizado com crianças, começa a trazer evidências que dão suporte a essa hipótese. Stappen e Reybroeck ${ }^{(30)}$ ao avaliarem o efeito de intervenções baseadas em treino de CF e NAR em crianças do $2^{\circ}$ ano mostraram que essas habilidades são independentes, ou seja, o treino em uma habilidade específica não impacta na melhora da habilidade que não foi treinada. Além disso, a intervenção de CF contribuiu para a diminuição da proporção de erros fonológicos durante a escrita, enquanto a intervenção de NAR contribuiu para a velocidade de leitura, sendo que esses efeitos se mantiveram por 6 meses ${ }^{(30)}$. Entretanto, até o momento não foi realizado nenhum estudo que investigou os efeitos de intervenções em NAR em adultos analfabetos funcionais.

É importante ressaltar que, apesar de existir uma grande variação na faixa etária dos participantes do presente estudo, essa medida não parece ter influência nos resultados em leitura. De fato, a análise de regressão, tendo a idade como variável independente, não foi capaz de aumentar a taxa de estimação do desempenho dos participantes no TCLPP. Outro motivo para manter um grupo com faixa etária tão heterogênea é de ser uma amostra representativa dos alunos matriculados na modalidade de educação de jovens e adultos no Brasil ${ }^{(14)}$.

Os resultados produzidos pelo presente estudo podem contribuir na compreensão dos processos cognitivos subjacentes à aquisição de leitura e escrita de adultos e, consequentemente, lançar luz para novas formas de intervenção para ensino de leitura em programas de alfabetização de adultos. Como visto, intervir em nomeação automática rápida pode ser uma nova possibilidade de prevenir e remediar dificuldades em leitura de adultos, podendo ser um novo tópico de investigações futuras.

Dentre as limitações do estudo destacam-se: tamanho da amostra reduzido e grande variação de idade dos participantes; escassez de instrumentos de inteligência com normas para adultos parcialmente alfabetizados; heterogeneidade em função do nível de leitura, pois alguns participantes eram capazes apenas de ler palavras isoladas, enquanto outros liam pequenos textos; ausência de instrumentos padronizados de avaliação de leitura que possibilite identificar com maior precisão o nível de analfabetismo funcional.

\section{CONCLUSÃO}

O presente estudo conclui que os adultos analfabetos funcionais apresentaram dificuldades em consciência fonológica, tendo pobre desempenho em tarefas que envolviam análise e manipulação de fonemas. Em nomeação automática rápida, apresentaram maior facilidade na nomeação de itens alfanuméricos. Em relação à leitura, houve dificuldades no processamento fonológico, apresentando erros por troca fonológica. As análises de correlação indicaram que nomeação automática rápida se correlaciona mais com o desempenho em leitura do grupo do que consciência fonológica. Por fim, a análise de regressão indicou que o desempenho em nomeação automática rápida pode explicar sozinho mais da metade do resultado em leitura dos participantes. De modo geral, pode-se afirmar que adultos analfabetos funcionais apresentam prejuízos nas habilidades avaliadas. Também é possível afirmar que nomeação automática rápida apresenta uma maior influência no desempenho em leitura dessa população.

\section{AGRADECIMENTOS}

À Fundação de Amparo à Pesquisa do Estado de São Paulo (FAPESP) pelo auxílio financeiro à pesquisa.

\section{REFERÊNCIAS}

1. UNESCO: United Nations Educational, Scientific and Cultural Organization. Literacy rates continue to rise from one generation to the next. Paris: Unesco; 2017

2. IBGE: Instituto Brasileiro de Geografia e Estatística. Pesquisa nacional por amostra de domicílios contínua: educação 2018. Rio de Janeiro: IBGE; 2019.

3. Ação Educativa, Instituto Paulo Montenegro. Indicador de alfabetismo funcional 2018: resultados preliminares. Instituto Paulo Montenegro e Ação Educativa; 2018.

4. Wagner RK, Torgesen JK. The nature of phonological processing and its causal role in the acquisition of reading skills. Psychol Bull. 1987;101(2):192212. http://dx.doi.org/10.1037/0033-2909.101.2.192.

5. Peterson RL, Arnett AB, Pennington BF, Byrne B, Samuelsson S, Olson RK. Literacy acquisition influences children's rapid automatized naming. Dev Sci. 2018;21(3):e12589. http://dx.doi.org/10.1111/desc.12589. PMid:28812316.

6. Vander Stappen C, Reybroeck MV. Phonological awareness and rapid automatized naming are independent phonological competencies with specific impacts on word reading and spelling: an intervention study. Front Psychol. 2018;9:320. http://dx.doi.org/10.3389/fpsyg.2018.00320. PMid:29593618.

7. Landgraf S, Beyer R, Hild I, Schneider N, Horn E, Schaadt G, et al. Impact of phonological processing skills on written language acquisition in illiterate adults. Dev Cogn Neurosci. 2012;2(Supl 1):S129-38. http:// dx.doi.org/10.1016/j.den.2011.11.006. PMid:22682902. 
8. Dehaene S, Cohen L, Morais J, Kolinsky R. Illiterate to literate: behavioural and cerebral changes induced by reading acquisition. Nat Rev Neurosci. 2015;16(4):234-44. http://dx.doi.org/10.1038/nrn3924. PMid:25783611.

9. Boltzmann M, Mohammadi B, Samii A, Münte TF, Rüsseler J. Structural changes in functionally illiterate adults after intensive training. Neuroscience. 2017;344:229-42. http://dx.doi.org/10.1016/j.neuroscience.2016.12.049. PMid:28069530.

10. Braga LW, Amemiya E, Tauil A, Suguieda D, Lacerda C, Klein E, et al. Tracking adult literacy acquisition with functional MRI: a single-case study. Mind Brain Educ. 2017;11(3):121-32. http://dx.doi.org/10.1111/ mbe. 12143 .

11. Araújo S, Fernandes T, Huettig F. Learning to read facilitates the retrieval of phonological representations in rapid automatized naming: evidence from unschooled illiterate, ex-illiterate, and schooled literate adults. Dev Sci. 2019;22(4):e12783. http://dx.doi.org/10.1111/desc.12783. PMid:30516315.

12. Bottino AG, Correa J. A compreensão leitora de jovens e adultos tardiamente escolarizados. Psicol Reflex Crit. 2013;26(2):405-13. http://dx.doi. org/10.1590/S0102-79722013000200021.

13. Corrêa MF, Cardoso-Martins C. O papel da consciência fonológica e da nomeação seriada rápida na alfabetização de adultos. Psicol Reflex Crit. 2012;25(4):802-8. http://dx.doi.org/10.1590/S0102-79722012000400020.

14. Todos Pela Educação. Anuário brasileiro da educação básica. São Paulo: Moderna; 2019.

15. Seabra AG, Capovilla FC. Teste de competência de leitura de palavras e pseudopalavras. São Paulo: Memnon; 2010.

16. Trentini CM, Yates DB, Heck VS. Escala de Inteligência Wechsler Abreviada (WASI): manual profissional. São Paulo: Casa do Psicólogo; 2014.

17. Lukasova K. Alterações fonológicas e motoras na dislexia do desenvolvimento [dissertação]. São Paulo: Universidade Presbiteriana Mackenzie; 2006.

18. Scarton CE, Aluísio SM. Análise da Inteligibilidade de textos via ferramentas de Processamento de Língua Natural: adaptando as métricas do Coh-Metrix para o Português. Linguamática. 2010;2(1):45-61.

19. Seabra AG, Capovilla FC. Prova de consciência fonológica por produção oral In: Seabra AG, Dias NM, editores. Avaliação neuropsicológica cognitiva: linguagem oral. São Paulo: Memnon; 2012.

20. Silva PB, Mecca TP, Macedo EC. Teste de Nomeação Automática - TENA: manual. São Paulo: Hogrefe; 2018.

21. Kolinsky R. How learning to read influences language and cognition. In: Pollatsek A, Treiman R. The Oxford handbook of reading. New York: Oxford University Press; 2015.
22. Yassuda MS, Diniz BSO, Flaks MK, Viola LF, Pereira FS, Nunes PV, et al. Neuropsychological profile of brazilian older adults with heterogeneous educational backgrounds. Arch Clin Neuropsychol. 2009;24(1):71-9. http:// dx.doi.org/10.1093/arclin/acp009. PMid:19041220.

23. Landgraf S, Beyer R, Pannekamp A, Schaadt G, Koch D, Foth M, et al Dissociating improvement of attention and intelligence during written language acquisition in adults. Int J Intell Sci. 2011;01(02):17-24. http:// dx.doi.org/10.4236/ijis.2011.12003.

24. Vágvölgyi R, Rohland LM, Sahlender M, Dresler T, Schrader J, Nuerk HC. Diversity of functional illiterate cases: results from a multiple-single case study. Z Erziehwiss. 2019;22(1):123-51. http://dx.doi.org/10.1007/ s11618-018-00863-z.

25. Dias NM, Minervino CASM, Reppold CT, Macedo EC, Seabra AG. Avaliação das estratégias de leitura em leitores típicos e disléxicos: abordagem neuropsicológica. Psicol Teor Prat. 2015;17(2):171-84. http:// dx.doi.org/10.15348/1980-6906/psicologia.v17n2p171-184.

26. Toledo Piza CM, Macedo EC, Miranda MC, Bueno OFA. Contrasting group analysis of Brazilian students with dyslexia and good readers using the computerized reading and writing assessment battery "BALE". Front Psychol. 2014;5:837. PMid:25132829.

27. Huettig F, Lachmann T, Reis A, Petersson KM. Distinguishing cause from effect: many deficits associated with developmental dyslexia may be a consequence of reduced and suboptimal reading experience. Lang Cogn Neurosci. 2018;33(3):333-50. http://dx.doi.org/10.1080/23273798.2017. 1348528.

28. Huettig F, Kolinsky R, Lachmann T. The culturally coopted brain: how literacy affects the human mind. Lang Cogn Neurosci. 2018;33(3):275-7. http://dx.doi.org/10.1080/23273798.2018.1425803.

29. Corrêa MF. Como os adultos aprendem a ler? Evidências de um estudo com adultos pouco alfabetizados e crianças com a mesma habilidade de leitura [dissertação]. Belo Horizonte: Universidade Federal de Minas Gerais; 2009.

30. Vander Stappen C, Reybroeck MV. Phonological awareness and rapid automatized naming are independent phonological competencies with specific impacts on word reading and spelling: an intervention study. Front Psychol. 2018;9:320. http://dx.doi.org/10.3389/fpsyg.2018.00320. PMid:29593618.

\section{Contribuição dos autores}

MSM foi responsável pelo delineamento do estudo, coletas de dados, análises estatísticas e escrita do manuscrito; ECM foi responsável pelo delineamento do estudo, análises estatísticas, escrita do manuscrito e supervisão do primeiro autor. 